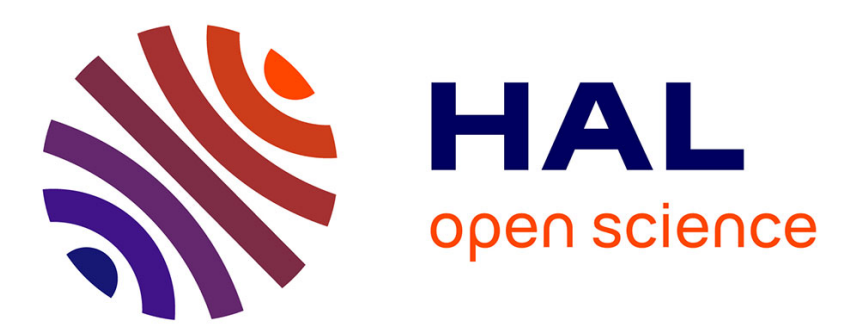

\title{
Comparing Local e-Government Websites in Canada and the UK
}

Laurence Brooks, Alexander Persaud

\section{To cite this version:}

Laurence Brooks, Alexander Persaud. Comparing Local e-Government Websites in Canada and the UK. 14th International Conference on Electronic Government (EGOV), Aug 2015, Thessaloniki, Greece. pp.291-304, 10.1007/978-3-319-22479-4_22 . hal-01412281

\section{HAL Id: hal-01412281 \\ https://hal.science/hal-01412281}

Submitted on 8 Dec 2016

HAL is a multi-disciplinary open access archive for the deposit and dissemination of scientific research documents, whether they are published or not. The documents may come from teaching and research institutions in France or abroad, or from public or private research centers.
L'archive ouverte pluridisciplinaire HAL, est destinée au dépôt et à la diffusion de documents scientifiques de niveau recherche, publiés ou non, émanant des établissements d'enseignement et de recherche français ou étrangers, des laboratoires publics ou privés. 


\title{
Comparing Local e-Government Websites in Canada and the UK
}

\author{
Laurence Brooks ${ }^{1}$ and Alexander Persaud ${ }^{2}$ \\ Department of Computer Science, Brunel University London, UK \\ $\left\{{ }^{1}\right.$ laurence.brooks@brunel.ac.uk; ${ }^{2} 1227294$ @my.brunel.ac.uk\}
}

\begin{abstract}
This paper provides an evaluation of eight local e-Government websites in Canada and the United Kingdom, utilizing web diagnostic tools. The results of the diagnostic evaluation are synthesized for a comparative case analysis between the various local e-Government websites, providing recommendations for areas of improvement in terms of accessibility. Furthermore, the study will offer insight into the varied approaches to e-Government website conceptualization and design among local officials. While eight local websites are evaluated, only the city of Calgary and Hillingdon are explored in-depth through interviews with local officials. The exploration of the use of web diagnostic tools as an evaluative method for local e-Government websites will supply local officials and webmasters with a valuable and feasible option for internal evaluation. The study is unique in that it evaluates multiple e-Government websites at a local level rather than a federal level between two countries.
\end{abstract}

Keywords: local e-government, web diagnostics, UK, Canada

\section{$1 \quad$ Introduction}

Over the last decade, increased expectations of online services can be attributed to the growth of e-Government services [3]. The dramatic growth in academic investigation of e-Government, as a field, provides significant opportunities to build upon existing research. Indeed, web developers' understanding of the conceptualization, delivery, management, and evaluation of e-Government is in a constant state of change as governments and their affiliates adopt new technologies, standards, and practices.

The internet has become an invaluable resource in the daily lives of citizens across the world, in both private and increasingly public sector services [4]. In acknowledging this appreciation, it is easily recognizable that e-Government practices are an important option for public access and engagement. Jati \& Dominic [5, p.85] state, 'The immediacy of the Web creates an immediate expectation of quality and rapid application delivery, but the technical complexities of a website and variances in the browser make testing and quality control more difficult, and in some ways, more subtle.' Whether it is at a local or federal level, governments have increasingly acknowledged the need for providing services through the Internet - commonly known as e-services [6]. With eGovernment services offered through web interfaces, evaluation has become a:

adfa, p. 1, 2011.

(C) Springer-Verlag Berlin Heidelberg 2011 
...necessary activity for ensuring returns from investments over time. Financial investment includes spending on equipment and technology necessary for delivering Web-based e-government services. Organizational investment, on the other hand tends to be unobservable, and includes the time and energy that government agencies need to rethinking, reorganizing and streamlining the service delivery system for the Webbased e-government initiatives [7, p.2].

While the scale of e-Government investment may not match initiatives at a federal level, local e-Government investment still must, '....be able to justify some form of return on investment, which typically requires evaluation of the Web-based e-government services' [7, p.2]. Early iterations of local city websites in the 1990s adopted a bureaucratic paradigm, where the website was administratively oriented. This has changed more recently as cities that have adopted, '...the e-government paradigm, design their Web sites differently' [8, p.434]. These new websites tend to use '...portal designs' [8, p.437].

Wang et al. [7, p.2] state that, '...despite the importance of the evaluation of Webbased e-government services, especially the performance of government Web sites in facilitating public-government interaction, little research has been generated', with most web-based service evaluation focusing on the private sector. Web diagnostic tools have become a method of evaluation for general websites and e-Government websites. Evaluative methodologies have been developed for e-Government websites (see [1], [9] and [7]). Other research studies have all specifically explored e-Government evaluations using web diagnostics at a federal level for multiple web portals $[5,6,10]$. Web diagnostic tools for local e-Government evaluation has significant room for further research and exploration as few studies investigate e-Government evaluation with web diagnostics, specifically at a local level.

This paper aims to provide a comparative case study analysis of local e-Government websites in Canada and the United Kingdom in terms of accessibility. In this context accessibility is defined in general terms as well as at a technical level. A comparative case study analysis will not only indicate the strengths and weaknesses of each respective website but will also suggest the varied or similar approaches local officials take in the conceptualization of e-Government websites in Canada and the United Kingdom. Eight local e-Government websites in Canada and the United Kingdom were evaluated using selected web diagnostic tools. The two localities selected for interviews were Calgary, Canada (http://www.calgary.ca/SitePages/cocis/default.aspx) and Hillingdon, UK (http://www.hillingdon.gov.uk/residents). The interviews conducted with local officials from Calgary and Hillingdon were relatively general, as a way to obtain unforeseen information.

\section{$2 \quad$ Literature Review}

\subsection{Conceptualizing e-Government Services}

In simple terms, e-Government services can, '...deliver information and services online through the Internet or other digital means', [11, p.64]. Venkatesh et al. elaborate, stating that: e-Government services can be broadly categorized into informational 
and transactional services. Informational services refer to the delivery of government information via web pages and transactional services involve two-way transactions between government and citizens (e.g. submission of electronic forms) that may require horizontal or vertical integration of multiple government agencies [12].

E-services are often centralized within a government portal where citizens can access a particular service. Kumar et al. state that the challenge of e-Government is not technical. It is '.. to use technologies to improve the capacities of government institutions, while improving the quality of life of citizens by redefining the relationship between citizens and their government' [11, p.64]. While e-Government has grown from being another option or choice for communication with citizens, global trends have made eGovernment a necessity for any country wishing to enter the $21^{\text {st }}$ century as a competitive nation. Beyond the functional benefits of citizen interaction, increased adoption of e-Government services have the potential for enormous savings and cost reduction (Kumar et al., 2007). Important considerations of web navigation, accessibility, aesthetics, and content fit within website design. An exemplary website design increases perceived usefulness and perceived ease of use among citizens, directly impacting e-Government adoption.

Certain user characteristics such as perceived risk and control may depend on perceptions of financial risk, psychological risk, social risk, convenience risk, and overall risk. The use of services may be discouraged due to perceptions of risk related to online security. In the case of the Canadian Government, trust via user identity is verified through an authentication code via the ePass government system, as well as the implementation of the Privacy Impact Assessment (PIA) Policy which outlines assessments for any new or redesigned service that may raise privacy issues [11]. Kumar et al. present a conceptualization framework for e-Government adoption in a Canadian context, though it can apply to other nations as well. Furthermore, while the conceptual framework may focus at a federal level, it can be applied at a local level due to the identification of important considerations in high-quality service delivery, engagement, and growth for e-Government in general.

The provided information and services via e-Government carry a vital purpose within the public sector, enabling citizens and businesses the completion of important and necessary tasks. It is therefore important that the conceptual design of e-Government services carry thoughtful consideration so that user satisfaction is maintained at a high standard. As more services are brought online, governments' ability to maintain accessible and usable services is important for user acceptance, satisfaction, and trust. The preference towards self-service can be partly attributed to the significant saving in time and effort, ease of use, and increased personal control [13]. With self-service in mind, e-Government websites require thoughtful design considerations to positively communicate usefulness, as they often act as an entry point towards available e-services. Wang et al. [7, p.2] acknowledge the financial benefits of e-Government service implementation in stating that in order to make investments worthwhile, '...government agencies must be able to justify some form of return on investment, which typically requires evaluation of the Web-based e-government services.' It is further noted that the performance of government websites in facilitating exchanges between the pub- 
lic and government agencies are directly related to the return on government's investment in its development of websites and delivered online services [7]. Wang et al. [7, p.2], state that, 'At a minimum, assuming the unit cost for a delivered service is less on a website than through alternative traditional means, each web interaction represents a cost savings.'

In recognizing the benefits of e-Government, its inevitable growth and ubiquity, and its importance in developing a meaningful relationship between government and citizens, government must ensure that its e-service websites are accessible and usable for adoption as well as overall customer satisfaction among citizens. However, even if the website provides the information necessary to complete the intended task and a consumer struggles when searching or retrieving desired information, the website will be abandoned [14]. The website must compensate for lack of physical contact experienced by online shoppers and at the same time make the shopping experience easy and enjoyable. In this context, online shoppers are citizens exploring e-services options. Great importance is placed on the perceived usefulness of a service.

\subsection{Methods of Evaluation for e-Government Service Websites}

Public authority web evaluation has seen few attempts to propose and use specific metrics for assessment [1]. Of the various criteria and metrics utilized, Wood et al. [2] describe 4 major classes of web evaluation methods, including usability testing, user feedback, usage data, and web and Internet performance data (Fig. 1). These methods relate to practical evaluation solutions that can work within an existing methodology. The authors identify the utilization of these four classes in creating a robust, multidimensional strategy to web-based evaluation of e-Government [2]. This multidimensional approach focuses particularly on web evaluation of e-Government websites rather than the conceptual assessment of web services [15]. The evaluation of e-Government websites can be attributed to both the Technical Performance and Site Quality layers.

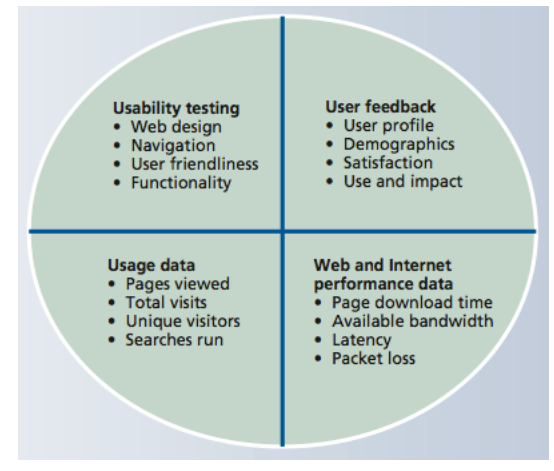

Fig. 1. A multidimensional approach to web evaluation [2].
Usability testing primarily involves feedback on website design, functionality, and navigation, wherein information can be obtained through methods of heuristic or expert review, informal usability testing, and usability lab testing [2]. Using a heuristic review encourages an independent, outside perspective towards website development, which provides web developers a larger context towards their considerations in web design. This can benefit the site layout and structure, navigation tools, search function, fonts and colors, among others. This type of usability testing allows a Web usability expert to review the website, compare it 
against generally accepted web design and functionality principles, and suggest design improvements.

Usage data is included among the variety of web evaluation classes with multiple methods including web log data analysis (in which web log software is installed on the website server to collect usage data such as page views, total visits, and unique visitors), and internet audience measurement (in which private companies collect usage data from large panels of web users who agree to have their web surfing monitored). Usage data can provide a range of quantitative data at relatively low cost and provide useful evidence of web trends in relation to the offered e-services.

Pearson et al. [16] identify 6 key criteria in evaluating web usability: Ease of use; Navigation; Accessibility; Download Speed; Gender; Customization and personalization. They state that navigation, download speed, personalization, ease of use, gender, and accessibility are integral to web usability evaluation. Navigation is an important consideration relative to consumer preference. Websites aim to achieve customization and personalization as a way of establishing an ongoing relationship with the customer. The findings recognize ease of use as the most important in assessing web usability while personalization and customization as less important. A clear emphasis is placed on the various criteria's impact on user satisfaction, with the most notable being download speed/technical performance. These criteria have commonalities with similar evaluative methodologies [1].

Panapoulou et al. [1] propose an evaluation framework that synthesizes five other authors' approaches to e-Government website evaluation (see fig. 2).

\begin{tabular}{|c|c|c|c|c|c|}
\hline & $\begin{array}{l}\text { Garcia et al } \\
\text { (2005) }\end{array}$ & $\begin{array}{l}\text { Smith } \\
(2001)\end{array}$ & $\begin{array}{l}\text { Holzer and Kim } \\
\text { (2005) }\end{array}$ & $\begin{array}{l}\text { Henriksson et al. } \\
\text { (2006) }\end{array}$ & $\begin{array}{l}\text { West } \\
\text { (2007) }\end{array}$ \\
\hline Content & $\boldsymbol{}$ & $\boldsymbol{}$ & $\boldsymbol{}$ & $\boldsymbol{}$ & $\boldsymbol{}$ \\
\hline Navigation & $\boldsymbol{}$ & $\boldsymbol{\nu}$ & $\boldsymbol{}$ & $\boldsymbol{}$ & $\boldsymbol{}$ \\
\hline Public outreach & $\boldsymbol{\nu}$ & $\boldsymbol{\nu}$ & $\boldsymbol{}$ & $\boldsymbol{}$ & $\boldsymbol{レ}$ \\
\hline Accessibility & $\boldsymbol{}$ & $\boldsymbol{\nu}$ & $\boldsymbol{\nu}$ & $\boldsymbol{\nu}$ & $\boldsymbol{\nu}$ \\
\hline Privacy and security & $\boldsymbol{\nu}$ & $\boldsymbol{\nu}$ & $\boldsymbol{\nu}$ & $\boldsymbol{\nu}$ & $\boldsymbol{\nu}$ \\
\hline Online services & & $\boldsymbol{\nu}$ & $\boldsymbol{}$ & $\boldsymbol{\nu}$ & $\boldsymbol{}$ \\
\hline Citizen participation & & & $\boldsymbol{\nu}$ & $\boldsymbol{\nu}$ & \\
\hline
\end{tabular}

Fig. 2. Concept matrix of e-government website evaluation methods [1].

The framework consists of three different levels of detail. The first (higher) level '...consists of four axes that measure four different aspects of e-Government websites...' while the second '....consists of factor that measure each distinct axis' [1], p.520).' The third level consists of the particular metrics used to carry out the evaluation. The highest level is titled the General characteristics axis, which include five factors with particular metrics of evaluation: accessibility (with metrics evaluating technical accessibility, accessibility for disabled and non-Internet savvy users), navigation (metrics evaluating searching capabilities, functionality and ease of use features, web page design consistency), multilingualism (metrics evaluating number of foreign languages and content completeness in them), privacy (metrics evaluating privacy statement, secure connections, information on data usage), and finally, public outreach (metrics evaluating contact information, response agility) [1]. This proposed framework provides a comprehensive overview of public authority/e-Government websites.

This synthesis of e-Government website evaluation literature includes public outreach, citizen participation, content, navigation, accessibility, privacy and security, and 
online services. Though these evaluative criteria provide a strong basis for e-Government website evaluation, the framework lacks an emphasis on technical performance aspects that heavily influence user satisfaction. The evaluation framework can add this seventh metric to provide a holistic overview and better gauge of e-Government website evaluation. In the context of local government websites, an updated Panapoulou et $a l$. framework incorporating the technical performance criteria described by Pearson $e t$ al. [16] constructs a suitable and well-rounded framework for evaluation. Perhaps the most important area of consideration for web developers is accessibility and usability, ensuring that navigation and content is clear and disability access, as well as technical aspects, are in compliance with popular web standards.

\section{$3 \quad$ Methodology}

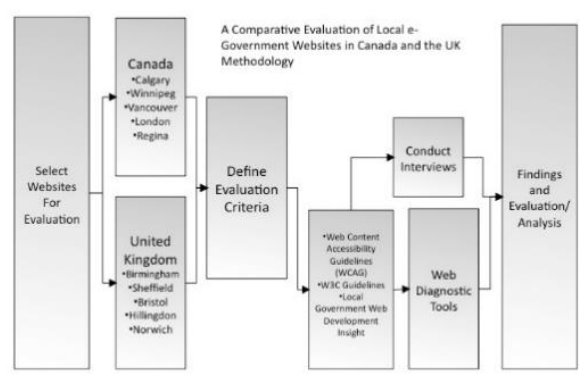

Fig. 3. The evaluative methodology used in the study.

A version of the iterative accessibility evaluation methodology from Al-Radaideh et al. [10], is used here, including selected websites from two countries. It also incorporates aspects from Fan, using interviews to provide further insight. This hybrid of quantitative and qualitative data provided a holistic perspective of local eGovernment accessibility considerations. In this case, web diagnostic tools are utilized to investigate local government website compliance with Web Content Accessibility Guidelines 2.0 (WCAG) and W3C

Guidelines, browser compatibility, acceptable markup language, and download times. Accessibility, in the context of the study, refers broadly to access to information and services as well as technically with consideration of disability access (e.g. visual impairment, etc). The results of the diagnostics offered comparative insight between local e-Government websites in Canada and the UK. As is the case with many previous eGovernment evaluations, web diagnostic tools were used to gauge accessibility and usability. The selected web diagnostic tools comprised of AChecker (http://achecker.ca), W3C Markup Validator (http://validator.w3.org), and Netmechanic (http://www.netmechanic.com).

\subsection{Selection of Local Government Websites for Evaluation}

The study investigated accessibility of local e-Government websites in Canada and the UK using web diagnostic tools. A total of ten e-Government websites (five in each nation) were carefully selected to provide a comprehensible and effective comparison between the two countries. The attributes of the cities that were considered had to be comparable, namely in size (in terms of population) as well as be representative of the country (in terms of geographical location), in order to account for inherent regional 
disparities. Furthermore, all local government websites had to offer e-services in order to be considered. With the decreasing significance of homepages (due to search engine queries and redirection), web diagnostic tools are utilized on e-service specified pages where less than two clicks are required to access an online service. The presence of eservices in the context of accessibility is important as it provides the study with insight into whether local government websites give all citizens the best chance of engaging with online services. An assumption was made that local government websites that have similar populations within their jurisdiction will have baseline similarities in budget, technical infrastructure, and resources in order to serve citizens effectively. In using population similarity, the scale of e-Government in terms of potential citizens served was balanced and fair. This process aided in the selection of websites for evaluation. Therefore, the results of the study better served comparisons between Canada and the UK. The local websites selected in Canada were, Calgary (http://www.calgary.ca), Vancouver (http://www.vancouver.ca), London (http://www.london.ca), Winnipeg (http://www.winnipeg.ca), and Regina (http://www.regina.ca). These Canadian cities were chosen to provide a broad geographic overview of the country and, for the most part, have comparable municipalities by measurement of population (ww12.statcan.gc.ca, 2015).

\begin{tabular}{|r|l|l|l|}
\hline$\#$ & City (CAN) & Province & Population \\
\hline 1 & Vancouver & British Columbia & $2,470,300$ \\
\hline 2 & Calgary & Alberta & $1,406,700$ \\
\hline 3 & Winnipeg & Manitoba & 782,600 \\
\hline 4 & London & Ontario & 502,400 \\
\hline 5 & Regina & Saskatchewan & 237,800 \\
\hline
\end{tabular}

Table 1. Canadian cities ranked by population (statcan.gc.ca, 2015).

The population mean of the selected Canadian cities is about 1,079,960 citizens. $50 \%$ of Canadian provinces are represented. The local websites selected in the United Kingdom were the London borough of Hillingdon (http://www.hillingdon.gov.uk), Birmingham (http://www.birmingham.gov.uk), Bristol (http://www.bristol.gov.uk), Sheffield (https://www.sheffield.gov.uk), and Norwich (http://www.norwich.gov.uk). The UK cities were similarly selected to provide a broad geographical overview of the country and provide a comparable average population size in relation to each other as well as the Canadian cities.

\begin{tabular}{|l|l|l|r|}
\hline$\#$ & City (UK) & Region & Population \\
\hline 1 & Birmingham & West Midlands & $2,453,700$ \\
\hline 2 & Sheffield & Yorkshire \& the Humber & 818,800 \\
\hline 3 & Bristol & Southwest England & 706,600 \\
\hline 4 & Hillingdon & London & 292,000 \\
\hline 5 & Norwich & East of England & 261,400 \\
\hline
\end{tabular}


Table 2. UK cities ranked by population 2013 (centreforcities, http://www.centreforcities.org/data-tool/\#graph=table\&city=showall\&indicator=population $\backslash$ single $\backslash 2013)$

The population mean of the selected English cities is 906,500 citizens. 55\% of English regions are represented.

With a comparable total population for citizens served across Canadian and United Kingdom regions, the selection of local government websites for evaluation provided a good foundation for a valid and meaningful study.

\subsection{WCAG Evaluative Criteria Background}

According to the W3C, the Web Content Accessibility Guidelines (WCAG) state: ...explain how to make Web content accessible to people with disabilities. The guidelines are intended for all Web content developers (page authors and site designers) and for developers of authoring tools. The primary goal of these guidelines is to promote accessibility. However, following them will also make Web content more available to all users, whatever user agent they are using (e.g., desktop browser, voice browser, mobile phone, automobile-based personal computer, etc.) or constraints they may be operating under (e.g., noisy surroundings, under- or over-illuminated rooms, in a hands-free environment, etc.). Following these guidelines will also help people find information on the Web more quickly. These guidelines do not discourage content developers from using images, video, etc., but rather explain how to make multimedia content more accessible to a wide audience (W3.org).

The WCAG 1.0 May 1999 guidelines were updated in December 2008 to 2.0 and further say it: covers a wide range of recommendations for making Web content more accessible. Following these guidelines will make content accessible to a wider range of people with disabilities, including blindness and low vision, deafness and hearing loss, learning disabilities, cognitive limitations, limited movement, speech disabilities, photosensitivity and combinations of these. Following these guidelines will also often make your Web content more usable to users in general (W3.org).

Though it is possible to conform either to WCAG 1.0 or to WCAG 2.0 (or both), the $\mathrm{W} 3 \mathrm{C}$ recommends that new and updated content use the latter. The $\mathrm{W} 3 \mathrm{C}$ also recommends that Web accessibility policies reference WCAG 2.0.

Web accessibility compliance is prioritized into three categories, as seen in Table 3. W3C symbols are used to certify web pages that meet Priority 1 ' $A$ ', Priority 2 'DoubleA', and Priority 3 'Triple-A' standards.

\begin{tabular}{|c|c|c|}
\hline Priority & Description & Symbols \\
\hline Priority 1 & $\begin{array}{l}\text { A Web content developer must satisfy } \\
\text { this checkpoint. Satisfying this checkpoint } \\
\text { is a basic requirement for some groups to } \\
\text { be able to use Web documents. }\end{array}$ & W3C WAI-A \\
\hline
\end{tabular}




\begin{tabular}{|l|l|l|}
\hline Priority 2 & $\begin{array}{c}\text { A Web content developer should satisfy } \\
\text { this checkpoint. Satisfying this checkpoint } \\
\text { will remove significant barriers to access- } \\
\text { ing Web documents. }\end{array}$ & W3' $\begin{array}{l}\text { WAI-AA } \\
\text { WCAG 1.0 }\end{array}$ \\
\hline Priority 3 & $\begin{array}{l}\text { A Web content developer may address } \\
\text { this checkpoint. Satisfying this checkpoint } \\
\text { will improve access to Web documents }\end{array}$ & W3 WAI-AAA \\
WCAG 1.0 \\
\hline
\end{tabular}

Table 3. WCAG Criteria Accessibility descriptions with WCAG 1.0 symbols (W3.org)

\subsection{Selection of Web Diagnostic Tools and Background}

The AChecker tool was chosen from the W3C recommended list of web accessibility evaluation tools (W3.org). AChecker was primarily chosen because of its free use and open source license. It provides evaluator diagnostic reports according to WCAG guidelines which can be exported in multiple formats. The AChecker can utilize WCAG 1.0 and 2.0 guidelines as well as Priority 1, 2, and 3 standards also known as 'A', 'Double-A', and 'Triple-A' (W3.org). While for each priority issues are categorized as 'Known Problems', 'Likely Problems', and 'Potential Problems' (achecker.ca), only 'Known Problems' were considered for this study.

The W3 Validator tool, also known as the W3C Markup Validation Service, checks the '...markup validity of Web documents in HTML, XHTML, SMIL, MathML...' and so on (validator.w3.org). The W3 Validator verifies websites in accordance with specified markup language rules. Markup validity implies a 'quality criteria for a Web page' among others (validator.w3.org). The important distinction is made that ' ... a valid Web page is not necessarily a good web page, but an invalid Web page has little chance of being a good web page (validator.w3.org).' For the purposes of the study, markup validity is one of the defined evaluation criteria when assessing local e-Government websites for accessibility and usability.

The third diagnostic tool, Netmechanic, conducts a free website speed test in which download time and browser compatibility are calculated (netmechanic.com). For this study, only download times for the selected e-Government websites were assessed at a standard $56 \mathrm{~K}$ connection speed.

The three selected web diagnostic tools offered a comprehensive overview of accessibility considerations. A clear insight into local e-Government websites' compliance to WCAG 2.0 standards as well as performance considerations (as described in previous studies) was gained through the utilization of these tools. As customer satisfaction is heavily dependent on web performance, usability, and accessibility, these tools play a critical role in ensuring proper implementation of local e-Government websites and access to e-services.

\subsection{Interviewees Selection and Approach}

To obtain added insight into the collected data via web diagnostic tools, interviews were conducted with web development officials in Canada and the United Kingdom, 
specifically in the localities of Calgary and Hillingdon. An interview was conducted with the team lead for web and digital services in Calgary. A joint interview between the project manager on the access channel migration team and team lead for web development in Hillingdon was also carried out. Interviews were recorded and performed in a semi-structured approach with prepared general, open-ended questions. The purpose of the interviews was to gain insight into the strategies regarding local e-Government website conceptualization, as well as, to learn of the special considerations that are made with regards to usability and accessibility towards services. For the interviews, qualitative data analysis took place through thematic analysis and data coding. The thematic analysis process begins with a collection of data, an identification of data that relate to classified patterns, sub-themes combination and cataloguing, and the construction of a valid argument for chosen themes based on related literature [17]. The identified themes in the study build upon those discussed in the literature review. The transcribed interviews categorized information into common themes of preset categories, although room was left to identify emergent categories. By codifying persistent themes, an identification of connections between categories and their relative importance was conducted with some visible overlap.

\subsection{Interview Analysis: Thematic Analysis}

Utilizing a thematic analysis method, interview transcripts were studied for common themes. Initially, preset data categories were used via Fan's local government study [18]. Fan's themes include 'top leadership support and management capacity', 'organizational and technical challenges', 'user-centred e-government approach', and 'bridging the digital divide' [18]. While these preconceived themes aided in categorization, new themes became apparent through further analysis. Through data coding and identification of subcategories, five major themes were identified from interview transcripts. These themes were, (1) a user-oriented approach, (2) organizational challenges, (3) integration expectations and challenges, (4) adaptation and growth of access channels, and (5) evaluative methods/tools. The fifth theme can be considered a subcategory of organizational challenges. The interviewees identified evaluative tools utilized for e-Government website improvement with statistic and analytic tools playing a major role in identifying web trends. Based on interview data, the Hillingdon web development team takes more into consideration with regards to accessibility at a technical level than the Calgary team. This is consistent with acquired web diagnostic data, indicating greater accessibility compliance in the UK.

\section{$4 \quad$ Findings}

\subsection{Diagnostic Results}

The following graphs show the results of the diagnostics on the Canadian and UK local e-Government websites, using AChecker, Netmechanic and W3 Validator. Both the UK and Canadian websites were both compared internally within country, as well as between countries. The results will also be discussed in light of their interpretation. 


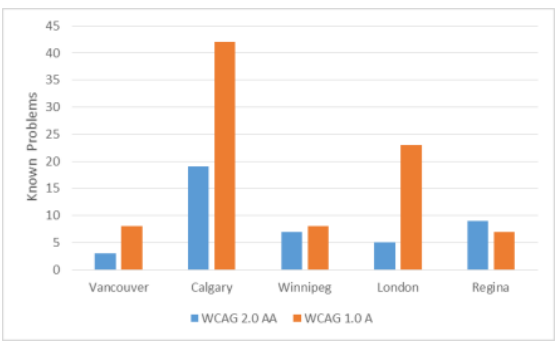

Fig. 4. AChecker results identifying known accessibility problems for Canadian local eGovernment websites, according to WCAG

Priority 1 - 'A' and WCAG Priority 2 'AA'

Graphs in Figs. 4 and 5 clearly show that Canada clearly leads known accessibility problems in terms of the WCAG metric.

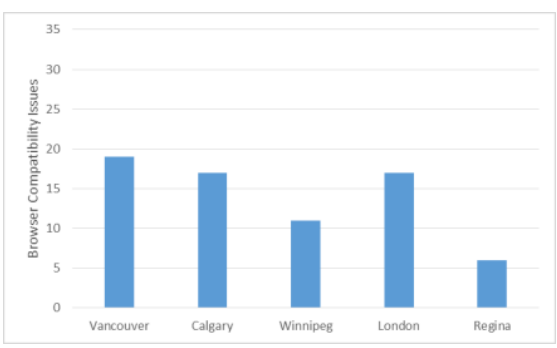

Fig. 6. Netmechanic results for browser compatibility issues for Canadian local e-Government websites

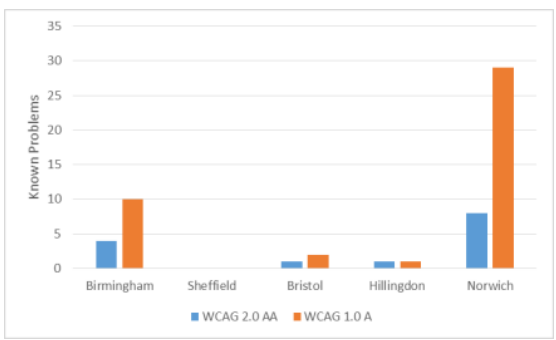

Fig. 5. AChecker results identifying known accessibility problems for UK local e-Government websites, according to WCAG Priority 1 - 'A' and WCAG Priority 2 - 'AA'

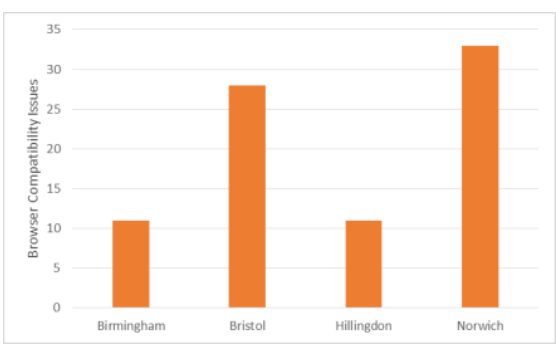

Fig. 7. Netmechanic results for browser compatibility issues for UK local e-Government websites

Graphs in Figs. 6 and 7 clearly show that the UK clearly leads in browser compatibility issues. The reverse is seen for an equivalent analysis of download times, with the UK having generally shorter download times.

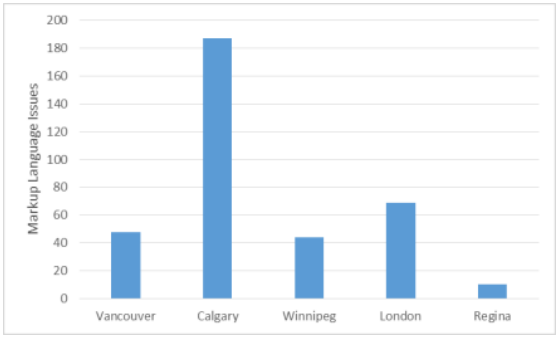

Fig. 8. W3 Validator results identifying browser markup language issues for Canadian local e-Government websites

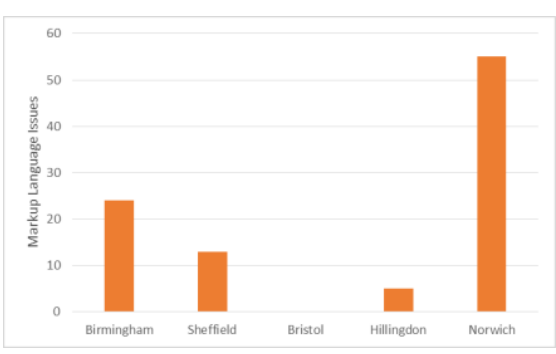

Fig. 9. W3 Validator results identifying browser markup language issues for UK local e-Government websites 
Graphs in Figs. 8 and 9 clearly show that overall Canada clearly leads in markup language issues.

\subsection{Results Overview}

The graphs illustrate the stark differences between Canada and the UK in the context of WCAG accessibility compliance metrics, with an overall advantage to the UK. The thematic analysis of interview transcripts produced five key areas of insight. Interviews were conducted with the purpose of providing insight into conceptualization of e-service delivery and accessibility. Interestingly, three out of four metrics of evaluation identified greater accessibility compliance in the UK. While diagnostic data identified an advantage in technical compliance, interview data suggested that the Canadian city of Calgary web and digital services team have a better integrated organizational structure, allowing for quick and responsive changes to e-service delivery. In short, while Calgary's technical presentation of e-services is relatively poor in terms of accessibility, its organizational structure allows for greater flexibility. Conversely, in the London borough of Hillingdon, there are more organizational challenges in managing third parties and integrating services. Third party services are presented and organized on Hillingdon's homepage, acting much more as a web portal in relation to Tat-Kei Ho's description of the user-oriented approach than Calgary's post-homepage user-oriented approach.

\section{$5 \quad$ Discussion and Conclusion}

The research builds upon evaluative e-Government studies using previous web diagnostic tools by $[5,6,9,10]$. Further, the study provided insight into local web development teams perspectives on user-oriented approaches, organizational and integration challenges, adaptation and growth of access channels, and evaluative methods and tools used. This interview approach emulated a previous investigation into local official insight regarding e-services conceptualization [18].

Future research opportunities include conducting interviews with other local officials to compare e-service conceptualization sentiment across regions. As interview data suggests, the homepage is no longer a major area of consideration in the delivery of e-services. Therefore, one can examine the implication of this shift in website presentation and what it means for accessibility at a technical and conceptual level.

This paper offered an exploration of the use of web diagnostic tools as an evaluative method for local e-Government websites, which provides local officials and webmasters a valuable and feasible option for internal evaluation. The results revealed greater accessibility compliance for local e-Government websites in the UK. For individual cities, interview data suggests the organizational structuring in Calgary better served effective, efficient, and responsive online service delivery as opposed to Hillingdon, which faces added organizational and integration challenges. For both parties, exploration of new access channel strategies and platforms provide encouraging prospects for the future of local e-Government development. 


\section{References}

1. Panopoulou, E., Tambouris, E., Tarabanis, K.: A framework for evaluating web sites of public authorities. In: Aslib Proceedings, pp. 517-546. Emerald Group Publishing Limited, (2008)

2. Wood, F., Siegel, E., LaCroix, E., Lyon, B., Benson, D., Cid, V., Fariss, S.: A practical approach to e-government Web evaluation. IT Professional 5, 22-28 (2003)

3. Heeks, R., Bailur, S.: Analyzing e-government research: Perspectives, philosophies, theories, methods, and practice. Government Information Quarterly 24, 243-265 (2007)

4. Henriksson, A., Yi, Y., Frost, B., Middleton, M.: Evaluation instrument for e-government websites. Electronic Government, an International Journal 4, 204-226 (2007)

5. Jati, H., Dominic, D.D.: Quality evaluation of e-government website using web diagnostic tools: Asian case. In: International Conference on Information Management and Engineering, (ICIME'09), pp. 85-89. IEEE, (2009)

6. Choudrie, J., Ghinea, G., Weerakkody, V.: Evaluating global e-government sites: A view using web diagnostics tools. e-Journal of e-Government 2, 105-114 (2004)

7. Wang, L., Bretschneider, S., Gant, J.: Evaluating web-based e-government services with a citizen-centric approach. In: Proceedings of the 38th Annual Hawaii International Conference on System Sciences. IEEE, (2005)

8. Tat-Kei Ho, A.: Reinventing local governments and the e-government initiative. Public administration review 62, 434-444 (2002)

9. Ma, H.-Y.T., Zaphiris, P.: The usability and content accessibility of the e-government in the UK. Universal access in HCI 760-764 (2003)

10. Al-Radaideh, M., Nuser, M., Wahbeh, A.: Evaluating Accessibility of Jordanian EGovernment Websites for People with Disabilities. In: Proceedings of International Conference on Information \& Communication Systems (ICICS), pp. 127-131. Citeseer, (2011)

11. Kumar, V., Mukerji, B., Butt, I., Persaud, A.: Factors for successful e-government adoption: a conceptual framework. The electronic journal of e-Government 5, 63-76 (2007)

12. Venkatesh, V., Chan, F.K., Thong, J.Y.: Designing e-government services: Key service attributes and citizens' preference structures. Journal of Operations Management 30, 116-133 (2012)

13. Meuter, M.L., Ostrom, A.L., Roundtree, R.I., Bitner, M.J.: Self-service technologies: understanding customer satisfaction with technology-based service encounters. Journal of marketing 64, 50-64 (2000)

14. McKinney, V., Yoon, K., Zahedi, F.M.: The measurement of web-customer satisfaction: An expectation and disconfirmation approach. Information systems research 13, 296-315 (2002)

15. Halaris, C., Magoutas, B., Papdomichelaki, X., Mentzas, G.: Classification and Synthesis of Quality Approaches in E- government Services. Internet Research 17, 378-401 (2007)

16. Pearson, J., Pearson, A., Green, D.: Determining the importance of key criteria in web usability. Management Research News 30, 816-828 (2007)

17. Taylor-Powell, E., Renner, M.: Analyzing qualitative data. University of Wisconsin-Extension, Cooperative Extension (2003)

18. Fan, Q.: An evaluation analysis of e-government development by local authorities in Australia. International Journal of Public Administration 34, 926-934 (2011) 